\title{
シリコン表面超構造における超伝導輸送現象
}

\author{
内橋 隆・吉澤 俊介 \\ 物質・材料研究機構 函 305-0044 茨城県つくば市並木 1-1 \\ （2014 年 11 月 29 日受付；2014 年 12 月 3 日掲載決定）
}

\section{Electron Transport in Superconducting Silicon Surface Reconstructions}

Takashi Uchinashi and Shunsuke Yoshizawa

National Institute for Materials Science, 1-1 Namiki, Tsukuba, Ibaraki 305-0044

(Received November 29, 2014 ; Accepted December 3, 2014)

\begin{abstract}
Silicon surface reconstructions with metal adatoms are two-dimensional systems with atomic-scale thickness. We have successfully measured the superconducting transition of a representative silicon surface reconstruction $\operatorname{Si}(111)-(\sqrt{7} \times \sqrt{3})$-In by electron transport measurement. In this article, we report our results together with the experimental techniques and future prospect for surface superconductors.
\end{abstract}

KEYWORDS : superconductivity, silicon, indium, surface reconstruction, electron transport

\section{1.は じめに}

シリコン表面は表面科学の中でも最も重要な研究対象 の一つであり, 特に単原子レベルの金属が吸着してでき た表面超構造は, その原子配列構造や電子状態が精力的 に研究されてきた ${ }^{1,2)}$ 。たとえば, $\mathrm{Si}(111)$ 表面上にインジ ウム原子が一次元的に配列してできる $\mathrm{Si}(111)-(4 \times 1)-\mathrm{In}$ 表面は室温では金属的な電子状態を有するが，約 $130 \mathrm{~K}$ の低温で構造相転移と共に絶縁体に相転移することが知 られている ${ }^{3 \sim 5)}$ 。この例から明らかなように, シリコン 表面（一般に半導体表面）での金属吸着超構造は単なる 金属薄膜とみなすことはできず，バルクとは異なる表面 原子層物質として扱うべきである。

このような半導体表面超構造の低温物性, 特に超伝導 の発現とその特性は非常に興味の持たれるところだが, ごく最近まではその答えはまったくわかっていなかっ た。その理由はいくつか考えられるが，最も大きな要因 は実験の困難さにあったと考えられる。すなわち，表面 超構造は大気暴露に対して非常に弱いので, 実験には超 高真空環境が必要だが，超伝導を調べるためにはへリウ ム温度程度の極低温環境が必要である。この二つの技術

E-mail : UCHIHASHI.Takashi@nims.go.jp
を共存させることは，必ずしも容易ではない。しかし， 近年の測定技術の進歩によって, 超高真空・極低温環境 での実験が可能になり, 特に走查トンネル顕微鏡 （STM）測定などでは一般的に行われるようになった。 よって, まさに現在, 表面超構造における超伝導を本格 的に研究する時期が到来しているといえる。本稿では, 半導体表面超構造の一種である $\mathrm{Si}(111)-(\sqrt{7} \times \sqrt{3})$-In 表 面で発現する超伝導について，われわれの電子輸送測定 の結果を中心に解説する ${ }^{6 \sim 8)}$ 。

\section{2. 表面系における超伝導研究}

本題に入る前に，これまでの表面系における超伝導研 究について簡単に振り返っておきたい。まず, 超高真空 環境で基板上に成長した金属超薄膜の超伝導がこれまで に調べられてきた。たとえば，原子レベルで平坦な鉛薄 膜内に形成される量子井戸状態が超伝導に影響を与え て, 膜厚の関数として転移温度 $\left(\mathrm{T}_{\mathrm{c}}\right)$ が振動する振る舞

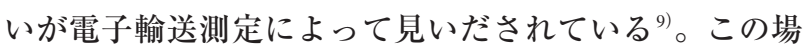
合の膜厚は 15 原子層（ML）以上であり，作製した試料 に保護層をとりつけてから大気中に取り出し, 汎用のク ライオスタットを用いて電子輸送測定を行った。さらに 膜厚が減って数 ML 程度の超薄膜になると, 超伝導は抑 制されて $\mathrm{T}_{\mathrm{c}}$ は下がっていくことが予想される。これは, 
一般に次元性が下がることによって摇らぎの効果が増 え, 超伝導転移には不利になるためである。バルク物質 でも有機導体や銅酸化物などで擬二次元物質が多く存在 するが，このような物質で超伝導が発現するには，面間 の相互作用が不可欠であると広く信じられていた。しか し，シリコン表面上の鉛超薄膜の STM 測定では, 数原 子層程度までほとんどバルクと変わらない超伝導ギャッ プの大きさが観測された ${ }^{10)}$ 。一方, 同じ系で膜厚の減少 とともに超伝導が抑制されるという報告もあり ${ }^{11)}$ ，この 相違の原因については不明である。

さらに膜厚が減って, 単原子層レベルになると, 前述 したようにもはや薄膜ではなく，基板表面と一体化した 表面超構造となる。このような場合にもやはり超伝導が 発現することが, Si (111) - $(\sqrt{7} \times \sqrt{3})-$-In, Si (111) $(\sqrt{7} \times \sqrt{3})-\mathrm{Pb}, \mathrm{Si}(111)-\mathrm{SIC}-\mathrm{Pb}$ 表面に対して STM 測定 によって発見された ${ }^{22}$ 。これは従来の超伝導と次元性に 関する固定観念を覆す重要な発見である。しかし， STM ではトンネル分光測定によってエネルギーギャッ プを見ているに過ぎず, 超伝導にとって最も重要な現象 であるゼロ抵抗を観測しているわけではない。よって, たとえば超伝導臨界電流值を STM によって測定するこ とはできない。また，銅酸化物などでは，いわゆる擬ギ ヤップ状態が観測され, エネルギーギャップの存在と超 伝導状態は必ずしも対応しない。電子輸送測定によっ て, 超伝導転移の直接的な証拠を得て, さらに重要な物 理量を決定することが，われわれの実験の目指したとこ ろだった。

\section{3. 表面超構造の超伝導：電子輸送測定}

\section{1 実験方法}

電子輸送測定によって超伝導転移を観測するために は, 試料に対する電極付けが不可欠である。通常のバル ク試料では, 大気中で銀ペーストなどによる電極付けを 行うが, 超高真空環境が必要な表面超構造では，このよ うな作業は不可能である。よって超高真空内で, 電気的 な接続をとるための何らかの手法が必要となる。この目 的のためにはこれまでに二つのアプローチが取られてき た。一つは，STM の探針を可動式のナノプローブとし て用いる方法であり ${ }^{13,14)}$ ，もう一つは試料基板上に固定

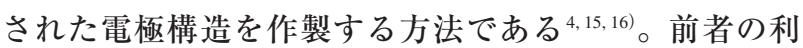
点としては電極の間隔を自由に調整し, 試料表面で測定 したい場所を選択できることであるが，一般にプローブ の接触には注意を払う必要があり, 特に大きな温度変化 を伴う測定では，温度ドリフトが影響を及ぼす。一方 で, 後者の方法では, 電極の間隔や位置を自由に選ぶこ とはできないが，一度安定した特性の良い電極が作製で
きれば，あとは温度や磁場などの外部制御パラメー夕を 自由に変化させることができる。本研究では, 後者の方 法を採用した。

Fig. 1 (a) にわれわれの用いた測定装置の外観を示 す。装置はロードロック・準備チャンバーと主チャンバ 一から構成されており，準備チャンバーには低速電子線 回折 (LEED) /オージェ電子分光 (AES) 装置などが備 わっていて, 表面科学における標準的な試料作製・評価 が可能である。作製した試料は，主チャンバーに移送し て，室温でSTMによって表面構造を確認した後，超高 真空対応クライオスタットに扦入して電子輸送測定を行 う。試料はヘリウムフローとポンピングによって冷却さ れ, 最低到達温度は $1.5 \mathrm{~K}$ である。室温からの熱輻射を 防ぐため，測定へッドはヘリウムのリターンで邻却され た輻射シールドで囲まれている。最近, この周りを液体 公素シールドで囲むことによって，試料温度をさらに下 げて安定化させることに成功した ${ }^{8}$ （Fig. 1（b）。極低 温度領域では, 熱接触が悪くなって, 比熱も非常に小さ

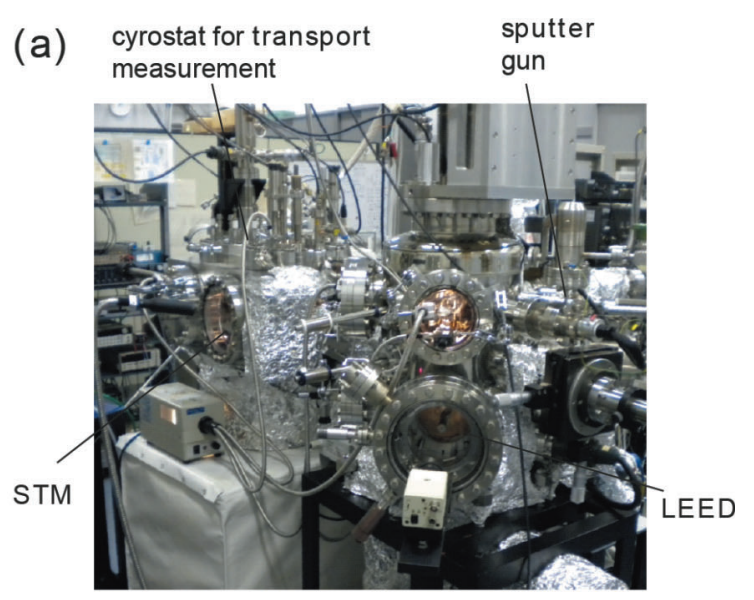

(b)

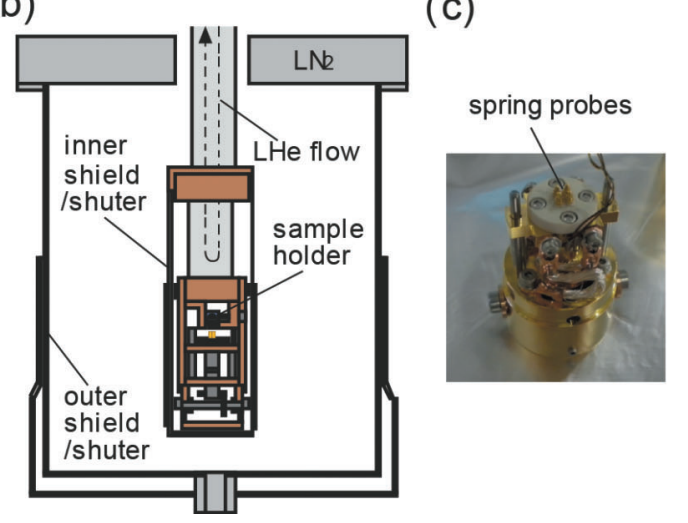

Fig. 1. (color online). (a) Photograph of the apparatus for UHV-LT-transport measurement. (b) Schematic illustration of the transport unit. (c) Photograph of the spring probes for electrical contact. 
くなるため, 精密な測定にはこのような工夫が必要とな る。

本害験に用いた表面超構造は $\mathrm{Si}(111)-(\sqrt{7} \times \sqrt{3})$-In で ある (以下 $(\sqrt{7} \times \sqrt{3})$-In と略記) ${ }^{17,18)}$ 。 $(\sqrt{7} \times \sqrt{3})$-Inには hex 型と rect 型の二種類があることが知られており，そ れぞれ，インジウム原子 1 層および 2 層から構成される と考元られている ${ }^{19 \sim 21)}$ 。本実験での $(\sqrt{7} \times \sqrt{3})$-In は，お そらく rect型であると思われるが, STM 像は hex 型の ように見え, 詳細な原子構造モデルについては未解決で ある。試料はノンドープの $\mathrm{Si}$ (111) 基板を高温フラッシ ユして清浄表面を出してからインジゥムを蒸着し, $300 \sim 400^{\circ} \mathrm{C}$ でアニールすることで作製した。試料調製 は, $(\sqrt{7} \times \sqrt{3})$-Inのドメイン構造が大きく成長し, 高い 結晶性が得られるように最適化した。Fig. 2 (a) (b) は 作製した $(\sqrt{7} \times \sqrt{3})$-In 表面の典型的な STM 像と LEED 像である。試料の調製後, 基板上に電子輸送測定に必要 な電極と伝導領域のパターンを作製した（Fig.2（c) (d))。これはシャドーマスクを介したアルゴンイオンス パッタによって，不要な領域を削りとることで行った。 電極パターンへの接触は，金コートされたスプリングプ ローブによって行った（Fig. 1 (c)）。スプリングによっ て試料との接触は温度を変化させても常に良好に保た れ，接触抵抗は数 $\Omega$ 以下である。

\section{$3.2(\sqrt{7} \times \sqrt{3})$-In 表面の超伝導転移}

Fig. 3 に $(\sqrt{7} \times \sqrt{3})$-In 表面に対して行った電子輸送測

(a)

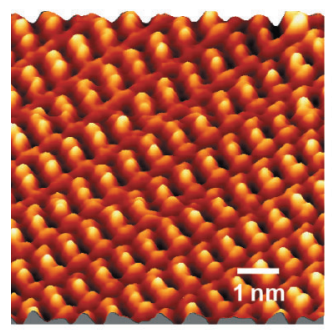

(c)

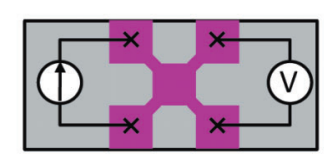

(d)
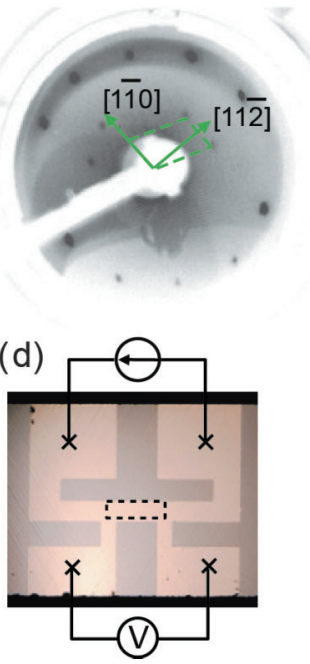

Fig. 2. (color online). (a) (b) Representative STM image (a) and LEED pattern (b) of the $(\sqrt{7} \times \sqrt{3})$-In surface. (c) Schematic illustration of the van der Pauw-type four-terminal measurement. (d) Photograph of the sample used for linear four-terminal measurement. 定の代表的な結果を示す6)。実験では，van der Pauw 型 の四端子測定を行った。すなわち，電流を流す領域を試 料中央の $1 \mathrm{~mm}$ 四方に制限し, 四隅に電流・電圧端子用 の電極パターンがつながるようになっている（Fig. 2 (c)）。電流の流す方向は $90^{\circ}$ 回転させて, 電気伝導の異 方性も調べることができるようにした。このグラフで表 示されている抵抗値は, 測定電圧をバイアス電流で単純 に割った值である。バイアス電流は $10 \mu \mathrm{A}$ と小さく, 常 伝導領域では, 線形な電流-電圧（I-V）特性をもつ。測 定は dc 測定で，オフセット電圧を除くためにバイアス 電流を反転させながら測定を行った。グラフからわかる ように, $\mathrm{T}_{\mathrm{c}}=2.8 \mathrm{~K}$ で明膫な超伝導転移が観測された。 電気伝導の異方性は少し見られるが, $90^{\circ}$ 回転した二つ の測定で, 全く同じ $\mathrm{T}_{\mathrm{c}}$ を示す。 $(\sqrt{7} \times \sqrt{3})$-In 表面は等 方的な電子状態をもつので ${ }^{18)}$ ，この異方性は後述する表 面原子ステップによるものと考えられる。

この実験を開始した頃は，ここで示したように $\mathrm{T}_{\mathrm{c}}=$ $2.8 \mathrm{~K}$ 程度が得られることが多く，その值もかなりばら ついていた。この原因は後に, 輻射シールドの隙間から わずかにもれて入ってくる輻射熱によって試料温度が上 がっているためであることがわかった。前述した液体窒 素シールドを装着することで, 現在では $\mathrm{T}_{\mathrm{c}}=3.05 \pm$ $0.04 \mathrm{~K}$ と求められており ${ }^{8)}$, STM 測定で報告された $\mathrm{T}_{\mathrm{c}}=3.18 \mathrm{~K}^{12)}$ との差はほぼ解消している。これは, 超高 真空・極低温環境での温度測定で一般的におこり得るこ とで, 注意が必要である。

ここで $\mathrm{T}>\mathrm{T}_{\mathrm{c}}$ の常伝導領域でのデータに注目してみ

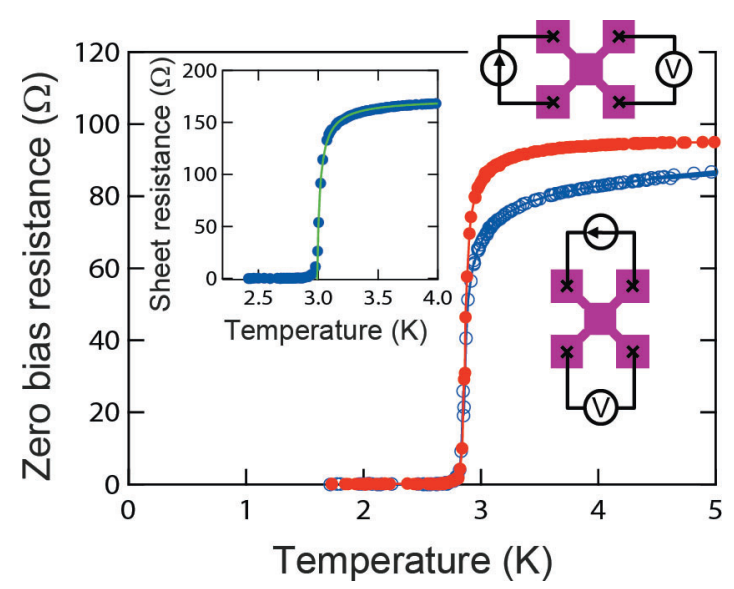

Fig. 3. (color online).Temperature dependences of the zero bias resistances of a $(\sqrt{7} \times \sqrt{3})$-In surface. The solid and open circles correspond to different configurations for the van der Pauw four-terminal measurement. (Inset) Temperature dependences of the sheet resistances of a $(\sqrt{7} \times \sqrt{3})$-In surface measured with linear four-terminal measurement. For details, see the text. 
(a)

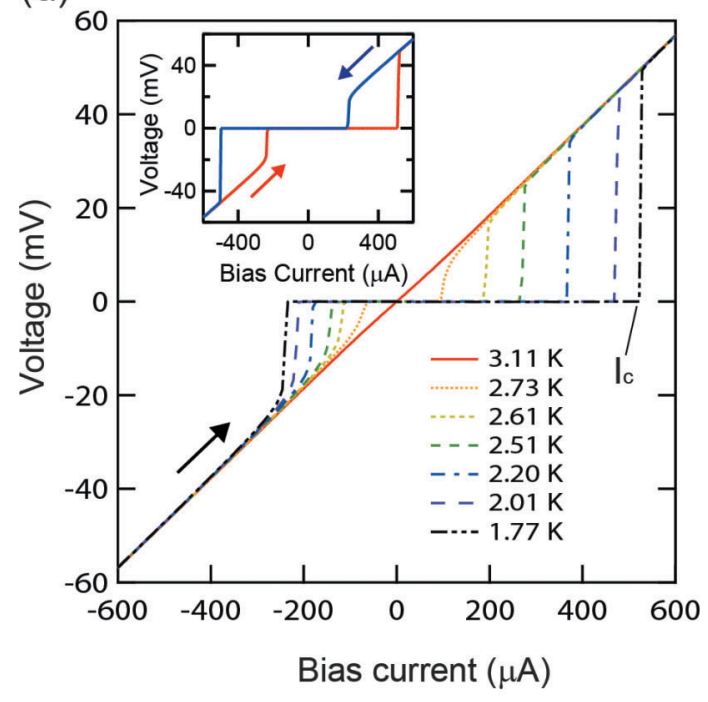

(b)

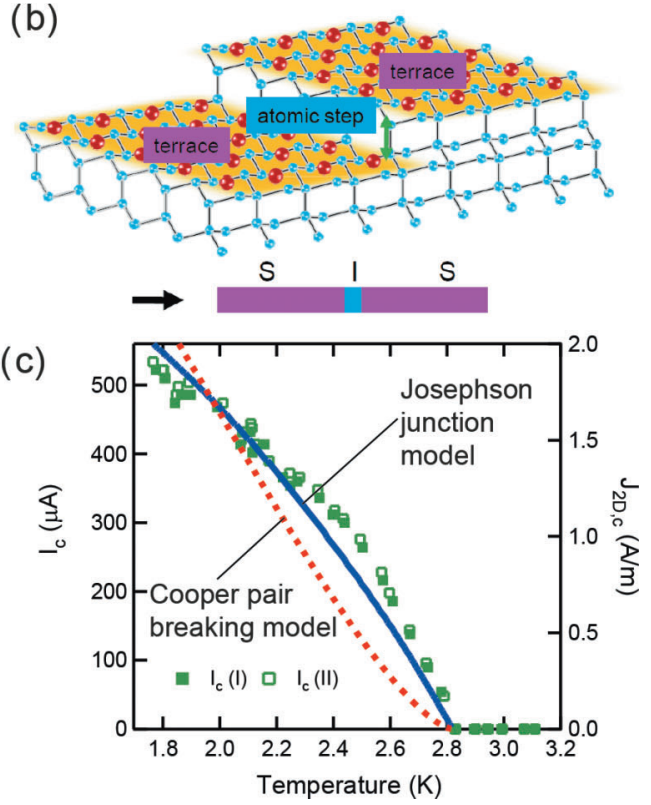

Fig. 4. (color online). (a) Temperature dependence of $\mathrm{I}-\mathrm{V}$ characteristics measured for the same sample used in Fig. 3. (Inset) Dependence on the sweeping direction of the bias current. (b) Schematic illustration of terraces and an atomic step consisting of a Josephson junction. (c) Temperature dependence of the critical supercurrent (left axis) and its density (right axis). The solid and broken lines are the fitting results based on two different theoretical model.

たい。試料内の電流分布を計算すると, グラフで表示さ れている抵抗値を面抵抗 (二次元伝導度) に変換するこ とができる。このようにして得られた面抵抗值は，常伝 導領域で約 $400 \Omega$ となる。これは, いわゆるクーパー ペアに対する量子抵抗 $\mathrm{h} / 4 \mathrm{e}^{2}=6.45 \times 10^{3} \Omega$ よりも十分に 小さい。一般に薄膜の二次元超伝導体では, 面抵抗值が この值よりも大きくなると, 系は絶縁体的な状態に転移 することが知られている $22 \%$ 。半導体表面超構造は理想 的な二次元系であるので, 当然この条件が適応される。 すなわち，本実験で明瞭な超伝導転移が観測できたの は, 面抵抗值が十分に量子抵抗よりも小さい, 結晶性の 高い試料をつくることができたためであるといえる。従 来の超伝導薄膜の実験では, 試料としては微粒子または アモルファスの薄膜しか得ることができなかったため, 膜厚が原子スケールになると面抵抗值が大きくなり, 絶 縁体化していたと思われる。結晶性の高い理想的な二次 元超伝導体をつくることができたのは, 表面科学におけ る半導体超構造の研究の蓄積があったおかげである。

また， $\mathrm{T}_{\mathrm{c}}$ 直上での抵抗の温度変化を見ると, 徐々に 抵抗の減少が加速していって, $\mathrm{T}_{\mathrm{c}}$ で急激にゼ口抵抗に 近づいていることがわかる。これは超伝導転移の前駆現 象であり， $\mathrm{T}_{\mathrm{c}}$ より高い温度でもクーパーペアが熱ゆら

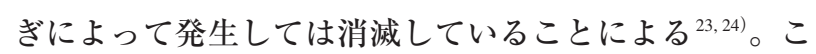
のゆらぎによる電気伝導度の成分 $\sigma_{\mathrm{sf}}(\mathrm{T})$ は低次元系で
増強され, 2 次元系では $\sigma_{\mathrm{sf}}(\mathrm{T})=\left(1 / \mathrm{R}_{0}\right) \mathrm{T} /\left(\mathrm{T}-\mathrm{T}_{\mathrm{c}}\right)$ と簡単 な式で表される $\left.\left(\mathrm{R}_{0}=16 \hbar / \mathrm{e}^{2}=65.8 \mathrm{k} \Omega\right)^{23}\right)$ 。より最近の ホールバー形状の四端子測定（Fig. 2(d) ) を行った害 験では，この摇らぎを取り入れた理論式によって抵抗值 の温度変化を解析し, 実験と理論の良い一致が得られて いる7)** (Fig. 3 挿入図)。

さらに $\mathrm{T}<\mathrm{T}_{\mathrm{c}}$ の超伝導領域を詳しく調べると, 実は $\mathrm{T}_{\mathrm{c}}$ では抵抗は完全にゼロにはなって扔らず，残留抵抗 が温度とともに減少していく振る舞いが観測されてい る7)。これは二次元超伝導体で生じる Kosterlitz-Thouless (KT) 転移の前駆現象と考えられる ${ }^{25)}$ 。KT 転移が生じ る温度 $\mathrm{T}_{\mathrm{K}}$ 以上では, 系は超伝導状態になっても熱摇ら ぎによって発生する超伝導渦が有限の抵抗をもたらす。 温度 $T_{K}$ ですべての渦は逆回転の渦と束縛状態をつくっ て，抵抗は完全にゼ口になる。このような振る舞いを観 察するためには, 浮遊磁場をなくすなどのより精密な測 定が必要となる。現在そのような実験を計画中である。

* 超伝導体が二次元的であるための条件は, 一般に膜 厚がコヒーレンス長（数 10 数 $100 \mathrm{~nm}$ ）より小さ いことであり, 必ずしも原子スケールの厚さを必要 としない。

**実際には摇らぎによって常伝導状態の電子の伝導度 が発散することによる寄与もあるため, $\sigma_{\mathrm{sf}}(\mathrm{T})$ の式 の $\mathrm{R}_{0}$ は見かけ上小さくなる。 


\subsection{I-V 特性と原子ステップジョセフソン接合}

これまでは，ゼロバイアス抵抗の測定結果を見てきた が, 電子輸送現象としては I-V 特性も重要である。Fig. 4 (a) に同じ試料の $\mathrm{I}-\mathrm{V}$ 特性の $\mathrm{T}_{\mathrm{c}}$ 近傍における温度変 化を示す ${ }^{6)}$ 。 $\mathrm{T}>\mathrm{T}_{\mathrm{c}}$ では線形だった特性が， $\mathrm{T}_{\mathrm{c}}$ 以下では ゼロバイアス付近でゼロ抵抗の超伝導領域が広がってい くことがわかる。バイアス電流を増加する途中で生じる 超伝導状態から常伝導状態への変化は急峻で, その閾値 から超伝導臨界電流 $\mathrm{I}_{\mathrm{c}}$ が定義できる。逆に常伝導状態 から超伝導状態へ変化する際の閾值も定義できるが，こ れは $\mathrm{I}_{\mathrm{c}}$ より小さくなっている。これは電流の掃引方向 を逆にしても同じで，すなわち $\mathrm{I}-\mathrm{V}$ 特性にヒステリシス が存在する (Fig.4 (a) の挿入図)。これは最初, 系が 常伝導状態にあるときはジュール熱によって試料の温度 が上がるため, 超伝導状態への転移が遅れるためである と考えている。すでに超伝導状態にあるときには，ジュ 一ル熱は発生しないので, 真の $I_{\mathrm{c}}$ まで超伝導状態が保 たれる。以下では， I cに注目して議論する。

Fig. 4 (c) に $\mathrm{I}_{\mathrm{c}}$ を温度の関数としてプロットした。グ ラフの右軸には, $\mathrm{I}_{\mathrm{c}}$ を二次元臨界電流密度 $\mathrm{J}_{2 \mathrm{D}, \mathrm{c}}$ に変換し たスケールで表示している。 $\mathrm{I}_{\mathrm{c},} \mathrm{J}_{2 \mathrm{D}, \mathrm{c}}$ は $\mathrm{T}_{\mathrm{c}}$ で立ち上がっ て温度の減少とともに増えていくが徐々に増加は緩やか になり，温度依存性は上に凸の形状を示す。ここで興味 のある問題は，微視的にみると臨界電流がどこで決まっ ているかである。可能性としては二つあって, 試料表面 上の原子ステップとテラスが考えられる (Fig. 4 (b))。 前者では，原子ステップがテラスの超伝導領域に対して 弱結合をもたらすジョセフソン接合として働くと考えら れ, 超伝導電流がジョセフソン臨界電流值を超えたとき に超伝導が破壊される。一方, 後者ではクーパー対が臨 界速度を超えて超伝導ギャップが破壊されることにより 生じる。この二つを表す理論式によってデータをフィッ ティングしたところ, 前者のジョセフソン接合モデルの 方がよく実験を説明することがわかった（Fig. 4（c）の 実線がジョセフソン接合モデル26), 点線がクーパー対破 壊モデル $\left.{ }^{27)}\right)$ 。また, フィッティングから原子ステップ の抵抗が $3.3 \times 10^{-4} \Omega \mathrm{m}$ と求められるが, この值は常伝 導状態での抵抗值から見積もったステップの抵抗值 $2.4 \times 10^{-4} \Omega \mathrm{m}$ に近い。これらの知見は電子輸送測定に よって初めて得られることを強調しておきたい。

原子ステップがジョセフソン接合として働くことは, 最近低温 STM 観察により, より直接的な形で確かめる ことができた ${ }^{28)}$ 。STM の微分伝導度測定モードを用い ると, 試料面直方向の磁場が侵入してできる超伝導渦を 観測できる。通常の超伝導渦は等方的な形状で, 中心で は超伝導が強く抑制されているが，原子ステップに入っ
た渦はステップ方向に伸張し, 中心での超伝導の抑制が 弱くなることがわかった。これは原子ステップが前述の ようにジョセフソン接合として働くことの帰結であ る ${ }^{29)}$ 。また，渦の流れは超伝導電流そのものであるの で，原子ステップを超えて超伝導電流が流れることを微 視的なスケールで確認することもできた

\section{4. を と め}

本稿では, $(\sqrt{7} \times \sqrt{3})$-In 表面における超伝導転移と電 子輸送測定について，われわれの穾験結果を中心に紹介 した。最後に今後の展開について述べたい。当然, 半導 体表面超構造は $(\sqrt{7} \times \sqrt{3})$-In 表面だけではなく, 多種多 様なものが存在するため, それらについて超伝導の発現 について調べていくことが考えられる。最近, $\mathrm{Si}(111)$ SIC-Pb 表面についても電子輸送測定によって超伝導転 移が観測された ${ }^{30)}$ 。また，超伝導を調べるためには，磁 場は重要な外部パラメータであり, 磁場中での実験もす でに行われている ${ }^{30,31)}$ 。さらに半導体超構造ではない が, $\mathrm{SrTiO}_{3}$ 基板上で成長した単ユニットセル $\mathrm{FeSe}$ 超薄 膜の $\mathrm{T}_{\mathrm{c}}$ が $40 \mathrm{~K}$ 以上にまで上昇するという驚くべき報告 がなされている32)。これは基板の影響が大きいと考えら れ，半導体超構造でも基板の効果が重要になるだろう。

バルク物質とは異なる, 表面での超伝導の特徽を考え る上で重要な点は以下の三つだと思われる。1）超伝導 特性が表面敏感になり得ること。これは，たとえば分子 吸着によって巨視的な超伝導特性を制御できる可能性が あることを意味する。2）完全な二次元性をもつこと。 たとえば面内方向に磁場を加えることで，クーパー対の 軌道対破壊効果を完全になくし，スピンに起因するパウ リ対破壊効果のみを検出することが可能になる。これに より，いわゆる Fulde-Ferrel-Larkin-Ovchinnikov（FFLO） 状態 ${ }^{33,34)}$ の穾験的検証も可能になる。3）表面での反転 対称性の破れによって, スピン軌道相互作用によってラ シュバスピン分裂が生じること。このような系では，超 伝導を担うクーパー対にはスピン一重項と三重項が混在 し, 超伝導の秩序パラメータが空間的に変調するなどの きわめて特異な状態をとることが理論的に知られてい る ${ }^{35)}$ 。半導体表面超構造では光電子分光などによって直 接に電子・スピン状態を調べることができるので，この ような特異な超伝導状態を調べるのに適しているかも知 れない。実際, 同様の系でラシュバ効果に起因すると思 われる現象が報告されている ${ }^{31,36)}$ 。今後，このような研 究を進める上で電子輸送測定がますます重要な役割を果 たすと期待される。

本稿で述べたわれわれの研究は, 文部科学省の世界卜 ップレベル研究拠点プログラム（WPI）と科学研究費助 
成事業（No. 25247053，No. 26610107）によって支援さ れました。また, 共同研究者である, Puneet Mishra, 中 山知信, 青野正和, 川上拓人, 永井佑紀, 胡暁, Kim Howon，長谷川幸雄の各氏に感謝します。

\section{文献}

1) V.G. Lifshits, A.A. Saranin and A.V. Zotov : "Surface Phases on Silicon: Preparation, Structures, and Properties” (Wiley, Chichester, 1994).

2) 長谷川修司 : 日本物理学会誌 54, 347 (1999).

3) H.W. Yeom, S. Takeda, E. Rotenberg, I. Matsuda, K. Horikoshi, J. Schaefer, C.M. Lee, S.D. Kevan, T. Ohta, T. Nagao and S. Hasegawa: Phys. Rev. Lett. 82, 4898 (1999).

4) T. Uchihashi and U. Ramsperger : Appl. Phys. Lett. 80, 4169 (2002).

5) T. Tanikawa, I. Matsuda, T. Kanagawa and S. Hasegawa : Phys. Rev. Lett. 93, 016801 (2004).

6) T. Uchihashi, P. Mishra, M. Aono and T. Nakayama : Phys. Rev. Lett. 107, 207001 (2011).

7) T. Uchihashi, P. Mishra and T. Nakayama : Nanoscale Res. Lett. 8, 167 (2013).

8) S. Yoshizawa and T. Uchihashi : J. Phys. Soc. Jap. 83, 065001 (2014).

9) Y. Guo, Y.F. Zhang, X.Y. Bao, T.Z. Han, Z. Tang, L.X. Zhang, W.G. Zhu, E.G. Wang, Q. Niu, Z.Q. Qiu, J.F. Jia, Z.X. Zhao and Q.K. Xue : Science 306, 1915 (2004).

10) S.Y. Qin, J. Kim, Q. Niu and C.K. Shih : Science 324, 1314 (2009).

11) C. Brun, I.P. Hong, F. Patthey, I. Sklyadneva, R. Heid, P. Echenique, K. Bohnen, E. Chulkov and W. -D. Schneider : Phys. Rev. Lett. 102, 207002 (2009).

12) T. Zhang, P. Cheng, W.J. Li, Y.J. Sun, G. Wang, X.G. Zhu, K. He, L.L. Wang, X.C. Ma, X. Chen, Y.Y. Wang, Y. Liu, H.Q. Lin, J.F. Jia and Q.K. Xue : Nat. Phys. 6, 104 (2010).

13) O. Kubo, Y. Shingaya, M. Nakaya, M. Aono and T. Nakayama: Appl. Phys. Lett. 88 (2006).

14) S. Yoshimoto, Y. Murata, K. Kubo, K. Tomita, K. Motoyoshi, T. Kimura, H. Okino, R. Hobara, I. Matsuda, S. Honda, M. Katayama and S. Hasegawa : Nano Lett. 7, 956 (2007).

15) K. Yoo and H.H. Weitering : Phys. Rev. Lett. 87, 026802 (2001).

16) C. Tegenkamp, Z. Kallassy, H. Pfnur, H.L. Gunter, V. Zielasek and M. Henzler : Phys. Rev. Lett. 95, 176804 (2005)

17) J. Kraft, S.L. Surnev and F.P. Netzer : Surf. Sci. 340, 36
(1995).

18) E. Rotenberg, H. Koh, K. Rossnagel, H. Yeom, J. Schäfer, B. Krenzer, M. Rocha and S. Kevan : Phys. Rev. Lett. 91, 246404 (2003).

19) A. Saranin, A. Zotov, M. Kishida, Y. Murata, S. Honda, M. Katayama, K. Oura, D. Gruznev, A. Visikovskiy and H. Tochihara : Phys. Rev. B 74, 035436 (2006).

20) J. Park and M. Kang : Phys. Rev. Lett. 109, 166102 (2012).

21) K. Uchida and A. Oshiyama : Phys. Rev. B 87, 165433 (2013).

22) A.M. Goldman and N. Markovic : Phys. Today 51, 39 (1998).

23) L.G. Aslamasov and A.I. Larkin : Phys. Lett. 26A, 238 (1968)

24) W.J. Skocpol and M. Tinkham : Rep. Prog. Phys. 38, 1049 (1975).

25) K. Epstein, A. Goldman and A. Kadin : Phys. Rev. B 26, 3950 (1982).

26) V. Ambegaokar and A. Baratoff : Phys. Rev. Lett. 10, 486 (1963).

27) J. Bardeen : Rev. Mod. Phys. 34, 667 (1962).

28) S. Yoshizawa, H. Kim, T. Kawakami, Y. Nagai, T. Nakayama, X. Hu, Y. Hasegawa and T. Uchihashi : Phys. Rev. Lett. 113, 247004 (2014).

29) G. Blatter, M.V. Feigel'man, V.B. Geshkenbein, A.I. Larkin and V.M. Vinokur : Rev. Mod. Phys. 66, 1125 (1994).

30) M. Yamada, T. Hirahara and S. Hasegawa : Phys. Rev. Lett. 110, 237001 (2013).

31) T. Sekihara, R. Masutomi and T. Okamoto : Phys. Rev. Lett. 111, 057005 (2013).

32) W.-H. Zhang, Y. Sun, J.-S. Zhang, F.-S. Li, M.-H. Guo, Y.-F. Zhao, H.-M. Zhang, J.-P. Peng, Y. Xing, H.-C. Wang, T. Fujita, A. Hirata, Z. Li, H. Ding, C.-J. Tang, M. Wang, Q.-Y. Wang, K. He, S.-H. Ji, X. Chen, J.-F. Wang, Z.-C. Xia, L. Li, Y.-Y. Wang, J. Wang, L.-L. Wang, M.W. Chen, Q.-K. Xue and X.-C. Ma : Chin. Phys. Lett. 31, 017401 (2014).

33) P. Fulde and R.A. Ferrell : Phys. Rev. 135, A550 (1964).

34) A.I. Larkin and Y.N. Ovchinnikov : Soviet Physics JetpUssr 20, 762 (1965).

35) E. Bauer and M. Sigrist (Eds.) : "Non-centrosymmetric Superconductors” (Springer-Verlag, Berlin Heidelberg, 2012).

36) C. Brun, T. Cren, V. Cherkez, F. Debontridder, S. Pons, D. Fokin, M.C. Tringides, S. Bozhko, L.B. Ioffe, B.L. Altshuler and D. Roditchev : Nat. Phys. 10, 444 (2014). 